\title{
EDITORIAL
}

\section{Laser-induced plasma and laser-induced breakdown spectroscopy (LIBS) in China: The challenge and the opportunity}

\author{
Jin $\mathrm{Yu}^{1, *}$, Ronger Zheng ${ }^{2, \dagger}$ \\ ${ }^{1}$ Department of Physics, Lyon 1 University, LASIM, 69622 Villeurbanne Cedex, France \\ ${ }^{2}$ College of Information Science \&5 Engineering, Ocean University of China, Qingdao 266100, China \\ E-mail: *jin.yu@univ-lyon1.fr, ${ }^{\dagger}$ rzheng@ouc.edu.cn \\ Received November 8, 2012; accepted November 14, 2012
}

Laser-induced plasma as a spectroscopic emission source was introduced only two years after the invention of the laser. By focusing a pulse delivered by a ruby laser on the surface of a solid target, Brech and Cross in 1962 first observed optical emission following the laser impact [1], which later had been further identified as the emission from the plasma produced during the laser ablation process of the impacted target. Spectroscopic analysis of the plasma emission immediately demonstrated its huge potential for direct chemical analysis by showing a rich spectrum consisting of specific lines from ions, atoms as well as molecules in the ablation plume [2]. The simplicity of the original concept leads to the intrinsic advantages of the analytical technique developed later according to the above mentioned pioneer works and generally called nowadays, laser-induced breakdown spectroscopy (LIBS). The versatility of laser ablation process enables LIBS to directly analyze all kinds of materials, whether solid, liquid or gas. Sampling and excitation by laser pulse together with detection of optical emission are fully compatible with stand-off operation. On the other hand, the ability of a laser beam to be tightly focused provides microanalysis feature of the technique. Last but not least, LIBS shares multiple elemental analysis capability with other analytical techniques based on emission spectroscopy.

Staying a laboratory curiosity up to the 1980's, LIBS has found its first applications with the developments in Los Alamos conducted by Radziemski and Cremers on the detection of hazardous airborne trace metallic or nonmetallic elements $[3,4]$. The development in the 1990's was more spectacular thanks to the technological progresses realized in laser, in spectrometer and in detector [5]. The further development turned to resolve very practical problems, such as monitoring environmental contaminations [6], controlling industrial processes $[7,8]$, or sorting waste materials [9]. With the first international LIBS conference held in 2000 in Pisa, Italy, the international LIBS community was established with the specific missions to make LIBS a mature technology and to develop its applications. A much larger range of demands in various domains has stimulated the development of the technique. In a

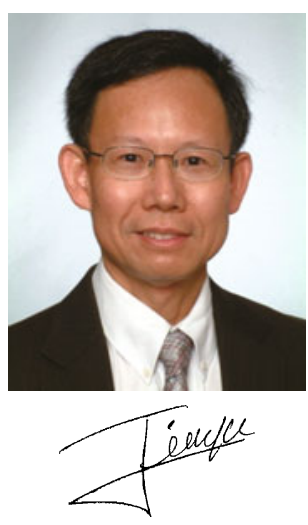

Professor Jin $\mathrm{Yu}$
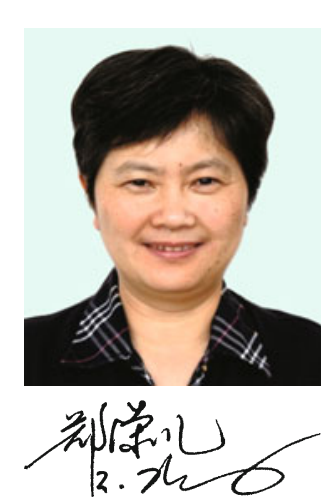

Professor Ronger Zheng non-exhaustive list, we can cite analysis of art works and cultural heritages for their conservation [10]; detection and analysis of bacteria $[11,12]$ and explosives $[13,14]$ for the needs from national security and homeland defence; direct analysis of trace metallic elements in fresh vegetables [15]; geological studies [16]; application in the nuclear industry [17]; and finally the space exploration with the integration by the NASA of the LIBS module, ChemCam, in Curiosity rover for the analysis of the soil on the Mars $[18,19]$.

The widespread and rapid development of LIBS applications contrasts however with its actual status of "between science and mature technology" [5]. Such contrast can be considered in parallel with that existing between the conceptual simplicity of the LIBS technique and the complexity of the physical processes involved in laser ablation and in expansion of the produced plasma into ambient gas. The requirement of a quantitative analysis with high performance is actually the major challenge faced by the international LIBS community to mature the technique. Back to the fundamental in order to reach a deeper understanding of the laser-induced plasma is considered today 
as the priority to trigger a significant breakthrough in LIBS technology [20, 21].

In such a context we welcomed the birth of the Chinese LIBS community. The first Chinese Symposium on LIBS (CSLIBS) held on March 26, 2011 in Ocean University of China in Qingdao was, at the same time, the first meeting of this community and a milestone in the development of LIBS in China. The participants of this conference wished to publish selected papers in order to make an inventory of LIBS research and development in China. Frontiers of Physics has kindly accepted the proposition of a special topic on LIBS gathering papers from several Chinese research teams (including a French team). This is the origin of the collection of the 8 papers which are now ready to be published in Frontiers of Physics. What the readers will discover through these papers is a picture of LIBS in China at that time. Draw a picture of an evolving community is obviously a difficult task. Such a special topic has at least the merit to present the state of the art of LIBS in China at a time when the Chinese LIBS community has started to write its own history. Among these 8 papers, 5 are review articles and the other 3 are research papers. The fundamental [22] as well as the application aspects are treated. Application papers occupy logically the major part of the special topic. Important domains of LIBS application developed in China have been reported concerning coal thermal power plant [23, 24], metallurgy [25], and national security [26]. The new configurations and variants of LIBS are also under investigation [27-29].

Beyond the inventory, clarifying the challenges as well as the opportunities is surely even more important for the Chinese LIBS community. Improving the quantitative analysis capability of LIBS and making it a mature technology accepted by a larger range of applications are the common vocation shared with the international LIBS community. The Chinese LIBS indeed faces its own opportunities with specific applications to develop in a country undergoing modernization. Huge and urgent demands are certainly the best asset of this community. Let us therefore wish a rapid and balanced development of LIBS in China, and hope that such development in turn actively contributes to the international LIBS community.

\section{References and notes}

1. F. Brech and L. Cross, Appl. Spectrosc., 1962, 16: 59

2. J. Debras-Guédon and N. Liodec, C. R. Acad. Sci., 1963, 257: 3336

3. D. A. Cremers and L. J. Radziemski, Anal. Chem., 1983, 55(8): 1252

4. D. A. Cremers and L. J. Radziemski, Appl. Spectrosc., 1985, 39(1): 57

5. L. J. Radziemski, Spectrochim. Acta B, 2002, 57(7): 1109

6. A. Ciucci, V. Palleschi, S. Rastelli, R. Barbini, R. Fantoni, A. Palucci, F. Colao, and S. Ribezzo, Appl. Phys. B, 1996, 63(2): 185

7. C. Aragon, J. A. Aguilera, and J. Campos, Appl. Spectrosc., 1993, 47(5): 606

8. M. Sabsabi and P. Cielo, Appl. Spectrosc., 1995, 49(4): 499

9. R. Sattmann, I. Mönch, H. Krause, R. Noll, S. Couris, A. Hatziapostolou, A. Mavromanolakis, C. Fotakis, E. Larrauri, and R. Miguel, Appl. Spectrosc., 1998, 52(3): 456

10. D. Anglos, Appl. Spectrosc., 2001, 55(6): 186A

11. C. Samuels, F. C. De Lucia, Jr., K. L. McNesby, and A. W. Miziolek, Appl. Opt., 2003, 42(30): 6205

12. M. Baudelet, L. Guyon, J. Yu, J. P. Wolf, T. Amodeo, E. Fréjafon, and P. Laloi, Appl. Phys. Lett., 2006, 88(6): 063901

13. F. C. De Lucia Jr., R.S. Harmon, K.L. McNesby, R. J. Wonkel Jr., and A.W. Miziolek, Appl. Opt., 2003, 42(30): 6148

14. C. Lopez-Moreno, S. Palanco, J. J. Laserna, F. DeLucia Jr., A. Miziolek, J. Rose, R. A. Walter, and A. I.Whitehouse, J. Anal. At. Spectrom., 2006, 21(1): 55

15. V. Juvé, R. Portelli, M. Boueri, M. Baudelet, and J. Yu, Spectrochim. Acta B, 2008, 63(10): 1047
16. Q. L. Ma, V. Motto-Ros, W. Q. Lei, M. Boueri, L. J. Zheng, H. P. Zeng, M. Bar-Matthews, A. Ayalon, G. Panczer, and J. Yu, Spectrochim. Acta B, 2010, 65(8): 707

17. A. Whitehouse, J. Young, I. M. Botheroyd, S. Lawson, C. P. Evans, and J. Wright, Spectrochim. Acta B, 2001, 56(6): 821

18. J. B. Sirven, B. Sallé, P. Mauchien, J. L. Lacour, S. Maurice, and G. Manhès, J. Anal. At. Spectrom., 2007, 22(12): 1471

19. http://msl-scicorner.jpl.nasa.gov/Instruments/ChemCam/

20. D. W. Hahn and N. Omenetto, Appl. Spectrosc., 2010, 64(12): $335 \mathrm{~A}$

21. D. W. Hahn and N. Omenetto, Appl. Spectrosc., 2012, 66(4): 347

22. J. Yu, Q. L. Ma, V. Motto-Ros, W. Q. Lei, X. C. Wang, and X. S. Bai, Front. Phys., 2012, 7(6): 649

23. L. Zhang, Z. Y. Hu, W. B. Yin, D. Huang, W. G. Ma, L. Dong, H. P. Wu, Z. X. Li, L. T. Xiao, and S. T. Jia, Front. Phys., 2012, 7(6): 690

24. Z. Wang, T. B. Yuan, S. L. Lui, Z. Y. Hou, X. W. Li, Z. Li, and W. D. Ni, Front. Phys., 2012, 7(6): 708

25. F. Z. Dong, X. L. Chen, Q. Wang, L. X. Sun, H. B. Yu, Y. X. Liang, J. G. Wang, Z. B. Ni, Z. H. Du, Y. W. Ma, and J. D. Lu, Front. Phys., 2012, 7(6): 679

26. Q. Q. Wang, K. Liu, H. Zhao, C. H. Ge, and Z. W. Huang, Front. Phys., 2012, 7(6): 701

27. Y. Cai, P. C. Chu, S. K. Ho, and N. H. Cheung, Front. Phys., 2012, 7(6): 670

28. Y. Zhang, Y. H. Jia, J. W. Chen, X. J. Shen, L. Zhao, C. Yang, Y. Y. Chen, Y. H. Zhang, and P. C. Han, Front. Phys., 2012, 7(6): 714

29. X. F. Li, W. D. Zhou, and Z. F. Cui, Front. Phys., 2012, 7(6): 721 